\title{
Correction: Giménez-Meseguer, J., Tortosa-Martínez, J., Cortell-Tormo, J. M. The Benefits of Physical Exercise on Mental Disorders and Quality of Life in Substance Use Disorders Patients. Systematic Review and Meta-Analysis. International Journal of Environment Research and Public Health. $2020,17,3680$
}

\author{
Jorge Giménez-Meseguer, Juan Tortosa-Martínez * and Juan M. Cortell-Tormo $\unrhd$ \\ Faculty of Education, University of Alicante, 03690 San Vicente del Raspeig, Spain; \\ jgimenezmeseguer@gmail.com (J.G.-M.); jm.cortell@gcloud.ua.es (J.M.C.-T.) \\ * Correspondence: juan.tortosa@gcloud.ua.es
}

Received: 8 July 2020; Accepted: 14 July 2020; Published: 17 July 2020

The authors wish to make the following corrections to this paper [1]:

On page 1, in the abstract, lines 17-22, the paragraph "An effect of exercise on mental disorders (standardized mean differences $(\mathrm{SMD})=0.66$ (confidence interval $(\mathrm{CI}): 0.46,0.86) ; \mathrm{z}=6.50 ; p<0.00001$ ) and quality of life (SMD $=0.69$ (95\% CI: 0.53, 0.84); $z=8.65 ; p<0.00001)$ was identified. Subgroup analysis revealed an effect of exercise in craving (SMD $=0.80$ (CI: 0.07, 1.53); $\mathrm{z}=2.15, p=0.03)$, stress $(\mathrm{SMD}=1.11(\mathrm{CI}: 0.31,1.91) ; \mathrm{z}=2.73 ; p=0.006)$, anxiety $(\mathrm{SMD}=0.50(\mathrm{CI}: 0.16,0.84) ; \mathrm{z}=2.88 ; p=0.004)$ and depression (SMD = 0.63 (CI: 0.34, 0.92); $\mathrm{z}=4.31 ; p<0.0001)$ " should be "An effect of exercise on quality of life and mental disorders was identified. Subgroup analysis revealed an effect of exercise on stress $(\mathrm{SMD}=1.11(\mathrm{CI}: 0.31,1.91) ; \mathrm{z}=2.73 ; p=0.006)$, anxiety $(\mathrm{SMD}=0.50(\mathrm{CI}: 0.16,0.84) ; \mathrm{z}=2.88$; $p=0.004)$ and depression (SMD $=0.63(\mathrm{CI}: 0.34,0.92) ; \mathrm{z}=4.31 ; p<0.0001)$, and an effect of exercise on the eight variables included in the SF36 test. The results also showed a trend towards a positive effect on craving $(\mathrm{SMD}=0.89(\mathrm{CI}:-0.05,1.82) ; \mathrm{z}=1.85, p=0.06)^{\prime \prime}$.

On page 23, lines 6-7, the sentence "The results show also a significant effect of exercise on craving $(\mathrm{k}=3 ; \mathrm{SMD}=0.80(\mathrm{CI}: 0.07,1.53) ; \mathrm{z}=2.15 ; p=0.03)$ " should be "The results also show a trend towards a positive effect of exercise on craving $(\mathrm{k}=3$; $\mathrm{SMD}=0.89$ (CI: $-0.05,1.82) ; \mathrm{z}=1.85 ; p=0.06)^{\prime \prime}$.

On page 29, lines 21-23, the sentence "Likewise, the results of the meta-analysis reinforce the conclusion that exercise can be a good way to reduce craving levels, finding a high effect of exercise on this variable" should be "The results of the meta-analysis show also a trend towards a positive effect of exercise on craving".

The authors would like to apologize for any inconvenience caused to the readers by these changes.

\section{Reference}

1. Mullard, A. The Benefits of Physical Exercise on Mental Disorders and Quality of Life in Substance Use Disorders Patients. Systematic Review and Meta-Analysis. Int. J. Environ. Res. Public Health 2020, 17, 3680. [CrossRef]

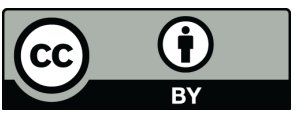

(C) 2020 by the authors. Licensee MDPI, Basel, Switzerland. This article is an open access article distributed under the terms and conditions of the Creative Commons Attribution (CC BY) license (http://creativecommons.org/licenses/by/4.0/). 